DOI: 10.17707/AgricultForest.65.3.14

\author{
Hasan PARSIPOUR, Svetislav G. POPOVIĆ, \\ Morteza BEHZADFAR, Goran SKATARIC, Velibor SPALEVIC ${ }^{1}$
}

\title{
CITIES EXPANSION AND LAND USE CHANGES OF AGRICULTURAL AND GARDEN LANDS IN PERI-URBAN VILLAGES (CASE STUDY: BOJNURD)
}

\begin{abstract}
SUMMARY
Sustainable development looking to reduce threats and harmful effects of economic, social and followed proper development patterns and preservation from lands in periphery cities. Urbanization in developing countries in comparison with developed countries accelerating the process has been increasingly and this problem caused to the physical expansion without any program in cities, leads to impose the harmful effects on the natural environment and agricultural lands in periphery cities. In Iran that share urban and rural population between 1941 to 2016 is contrary from 31.5 per cent to 74 percent have physical changes such as expansion of cities and merged or dissolve villages in cities space and swallowing agricultural lands and gardens in periphery cities. Bojnurd city in North Khorasan province with 2,584 hectares moved toward dissipated growth pattern with modernism paradigm and with accepting urban sprawl pattern swelled of peripheral lands and this issue increased in recent years. Four villages include Halghehsang, Malkesh, Yengeghalee and Bagherkhan 3 were added to the city services margin from 2009. Results shows decreasing in gross urban density from 153.6 to 65.3 per cent in the period from 1941 to 2016. This issue caused that sprawl growth pattern in this city swallowing lands. These lands mainly are agricultural lands and gardens. Reviews on city creep phenomenon in Bojnurd with urban sprawl development pattern shows that this pattern will continue due to promotion of Bojnurd city to the capital of North Khorasan province and acceptance of new superior role and capacity of new regional investment and job creation in the upcoming decades. The other villages like Yngehghalee, Bagherkhan3 will swallow the peri-city lands and the productive role of these villages will changed to services. Therefore, sustainable development and preservation of lands surrounding the city should change sprawl urban pattern in Bojnurd city and replaced by a pattern of smart growth that forms the ideal city is a compact city
\end{abstract}

\footnotetext{
${ }^{1}$ Hasan Parsipour, Planning and Budgeting Organization of North Khorasan, IRAN; Svetislav G. Popović, University of Montenegro, Faculty of Architecture, Džordža Vašingtona Street bb, 81000 Podgorica, MONTENEGRO; Morteza Behzadfar, Planning and Budgeting Organization of North Khorasan, IRAN *(corresponding author: mbehzadfar@gmail.com); Goran Skataric, National parks of Montenegro, Podgorica, MONTENEGRO; Velibor Spalevic, University of Montenegro, Faculty of Philosophy, Danila Bojovica, Niksic, MONTENEGRO.

Notes: The authors declare that they have no conflicts of interest. Authorship Form signed online.
} 
that will search development at within the city. This pattern emphasis on preserving agricultural lands within and outside the city. The fact is 24 percent of city space belongs public lands and gross city density is 71.5 person. Therefore, it is not recommended any increasing in city limits because more than 50 per cent of the surrounded lands include agricultural lands and gardens are in the immediate vicinity of the city.

Keywords: Agricultural lands, Garden, land use change, Peri-urban villages, Sprawl development, Bojnurd

\section{INTRODUCTION}

By emerging industrial revolution in $18^{\text {th }}$ and $19^{\text {th }}$ century, Cities and surrounded villages experienced vast evolutions. After the second world war, the main scheme of cities growth was the machinery and dissipated urban development. These types of developments led to degrading and emitting agricultural lands especially clear cutting gardens and also some problems to support facilities and environmental crisis (Rahnam and Abbaszadeh, 2008). As a result, policy makers are trying to preserve environment and settle environmentally friend cities based on sustainable development thought and ecofriendly cities as a world awakening (Mahdizadeh, 2011).

Urbanization and agriculture are two different cases which are completely related together as all researchers believe in the necessity of existence of surplus agricultural products in appearing of cities in history (Harvey, 1992). But today the relationship of these two has reached a specific level. With the fast increase of urbanization and the continuous raise in population, we could not only see that big cities are appearing but also with this expansion toward existing biological the spaces, it would cause irreversible damages in agricultural lands and gardens and even these incorrect plans will occasion that the suburb villages turn into informal settlements in transition phase of rural nature into urban nature (Daneshpour,2006).

The sharp rise in urban population and subsequent irrepressible physical development of cities in recent decades are some of the threats that are occupying habitations and sustainable urban development is a case looking for proper patterns of development and suburb lands preservation in order to reduce these threats and the harmful economic social impacts of them.

Urbanization in developing countries in comparison with developed countries has been accelerating and this has caused by unplanned physical expansion results in more harmful undesirable effects on natural environments and the agricultural lands around and the trouble which is happening a serious treatment of urban-rural prospective.

In I.R.Iran where the rural and urban population rate was reversed between 1941 and 2016 and urbanization grew from 31.5 to 68.5 percent, some changes such as physical expansion and merging the suburb villages and swallowing the agricultural lands and gardens appeared. 
Peri-urban environments are some spaces where are strongly under effect of daily growth of urban population and experience constitutional changes. Firstly, their land use which turns from agricultural and husbandry into residential use and secondly they merge with urban fabric that the main reason of this phase are comparative low life expenses especially the costs of land and house in these villages and emigrants' tendency toward these areas.

The purpose and subject of this research is analyzing and presenting the general and comprehensive image of growth model of Bojnurd and land use changes consequent by this growth in the villages around the city which on one hand the physical growth process of the city and on the other hand the physical growth and expansion process of the villages will be studied and the main question in this research is that "is there any relationship between the physical growth model of cities and land use changes of the villages around them?" And to answer to this question, a hypothesis is given that the model of sprawl growth and expansion of Bojnurd is the rational of land use change if agricultural lands and gardens of the suburb villages.

\section{Records and revision of previous researches}

Based on several researches accomplished about different cities, physical development and expansion of cities was the main factor of changes in peri-city residential function and also in land use which will be mentioned below.

A research about development and expansion of Tehran has been accomplished showing that along city growth, the villages in its influence domain and around it face lots of changes in their functions which sometimes led to appearing of new villages (Rahnamayi,1990,24-53) and also in this process some villages around Tehran such as Hesarak, Vanak, Darabad, Darband, Saadatabad, Velenjak, etc were swollen which sometimes caused to appearance of newly born informal settlements for example Abkouh Castle in Mashhad (Saeedi Rezvani,2006).

Analysis of Sanandaj space development in last 3 decades shows that 8 villages including all their agricultural lands and gardens and farms were merged with city fabric (Zia Tavana and Ghadmarzi, 2005) that the most important characteristics of these villages were lack of urban installations, facilities and services (Farhoudi and Mohamadi,2005).

The analysis of physical development of Tabriz in last 4 decades shows that irrepressible expansion of this metropolis had a wide range of changes specifically through changing land use of agricultural land and gardens and turning them into residential land use in influence domain villages especially along the communication paths of this city (Zaheri,2008).

The study which has been done in valley settlements of Skochai, Azarbayejan shows that in a 13-year period (1989-2002), the population raised almost 12 per cent meanwhile approximately 77 per cent was added to the construction space in the area of study and in this process there is a dramatic decline in the space of gardens and agricultural lands for the interest of 
residential land use and none agricultural land use (Sadr Mosavi \& Ghorbani, 2007).

Another research has been done to analyze the construction of the new industrial city of Alborz and the influences of its change on Alvand villages that the results indicate constitutional direct effects of city development on economic, social and spatial, somatic and environmental changes of the influence domain villages which are resulted by expansion of industrial units (Soleymani,2002).

Physical Expansion process of our cities is growing sharply at the moment as one study shows that the fast sprawl development of Yazd between 1983 to 2006 and the continuance of its center-suburb movement are accelerating and in spite of spongy fabric and existence of the major number of idle lands in it, the lands around the city are being swallowed by this physical expansion (Azizpour,2009) and this matter is admitted by the comparison 4 percent growth and 8 percent space growth and this problem is the reason why 21 percent of city space is turned into idle land use (Taghvayi and Sarabi, 2004).

There is a study related to the subject matter done in village area about analysis of rural infrastructure development plans and the process of construction in Chenaran. Results shows that the construction in agricultural lands instead of specified lands in the direction of predicted expansion plans is still in progress which has caused to an increase in urban problems (Yasouri,2009)

\section{Research theoretical foundation}

Urbanization is defined by some experts based on its communication and in this case David Harvey believes that every city includes environs and no centre could be imagined without the environs and these two help each other to be defined (Harvey,2003). Based on Hamilton and Anas (2008) decentralized development of cities leads to activity and population replacement. So, travel time and costs will increase and cause to pollution and urban problems (Bestani \& Klein, 2006). The main issue is decentralized development of cities being to the main problem of developing countrie especially in Asia and Africa (Musallam, 2012).

Somatic and physical growth of a city is a progress which takes place in 2 general structures of internal and external and the international searches show that compact city approach is nearer to the aims of sustainable development (Masnavi,2003). External city expansion is appeared like city limit increase or sprawl and internal expansion like compact city growth pattern which is connected to urban smart growth.

City smart growth is a method which mentions expansion principles and set piece related with land use pattern and transportation. Smart growth finally ends in vertical expansion pattern and compactness in cities which occupies less land space and with use of different types of transportation makes a decrease in traffic and journeys.

Some advantages of compact cities are decreasing the distance of facilities and job opportunities and nearing free time to each other and finally saving fuel and efficient use of urban lands and protecting agricultural and rural lands around 
city (Jurgis,2007), overhauling old buildings and abandoned lands, increasing mobilization resulted by transportation increase and creating social spirit by merging land uses (Zenonas,2006).

In developed countries a lots of methods and patterns related to strategies of protecting agricultural lands, gardens and green lands are used which are divided in to groups: suburban and intercity. Suburban strategies such as green rings and bows are accomplished to save suburb agricultural lands and limit irrepressible growth of cities. Intercity strategies such as method of economic revenue operation of agricultural lands and gardens with the purpose of providing some needs of city habitants.

The method of transferable development law which is used to prevent agricultural lands and gardens land use change into residential land use is provided for owners and farmers and subsequently land use change of agricultural lands and gardens would be forbidden and method of ecological benefits and tax support which is resulted by the desired effect of these lands on weather modification and protecting urban landscapes help these owners to be included in these supports and different tax discounts. (Sadr Mosavi \& Ghorbani, 2006).

\section{MATERIALS AND METHODS}

In this research the method of descriptive-analytical method is taken to analyze and explain connections and communications of Bojnurd and the villages around it and documentary method is taken for analyzing its changes and transitions and because the final aim is operational kind, these two methods are merged with desk and survey methods.

In order to analyze process of somatic expansion of the city and progress of swallowing the villages located in peri-city domain, first level of the research was spent on desk research and analysis of aerial pictures and maps of different periods and after collecting information and data and categorizing them, by using direct observation method, second level was spent on completing information and finally by merging and analyzing the existing information, assessment and analysis of existing growth model and pattern of the city was accomplished to find the best physical expansion pattern for the city coincided with sustainable urban expansion on one side and on the other side with sustainable rural expansion. The area of study in this research is urban area of Bojnurd and pericity domain villages which are merged with urban fabric and immediate villages.

\section{RESULTS AND DISCUSSIONS}

There is a wide fertile valley located on the north of Khorasan from West to east and is surrounded by Kopedagh and Hezarmasjed mountains in the north and Aladagh-Binaloud in the South.

Alongside this building hole, there are some small and medium sized plains where sediments accumulation has made appropriate agricultural domains in and has prepared the base of city creation and expansion of some cities including Bojnurd. Bojnurd is located in 57 $20^{\prime}$ latitude and $37^{\circ} 29^{\prime}$ longitude 
and is 1070 meters higher than see level and is limited by faults in North and South West and by dry rivers in North and East (Fajre tose'eh,2007).

Population: according to the census data collected in 2016, the population of Bojnurd is 228931 (Statistical Centre of Iran, 2016) that is calculated 186297 by urban comprehensive plan of Bojnurd with ratification of its city proper and attaching 3 villages to the city in 1388 (Naghshe Jahane Pars, 2009).

Urbanization ranking of this city didn't fluctuate a lot in urban order system from 1941 to 2016 and went up from ranking 54th in 1941 to 42th in 2016 as this city is in the population class of 100,000 to 499,000 people and is known as a city with an average population or middle city.

Occupation: In 2016, Classification of occupants based on main activities showed from 58977 people (10 and over 10 years old) who lived in the city were 9 per cent work in agriculture part, 26 percent in industrial part, 63 in service part and 2 percent in unknown part.

Assessment of economic status of the city expresses a transition in economic structure of the city which has changed from economic status dependent on agriculture into industry and service expansion and specifying a major space of town to industrial and service occupations has caused some changes in somatic structure and land use pattern.

Somatic structure: assessment of population increase process and alongside it expansion of city space between the years 1941 and 2009 indicates on acceleration of city space increase in comparison with population increase as gross urban density has had a decline from 153.6 people per hectare to 65.3 people per hectare (table 1 ) and this problem is obvious in comprehensive plans of 1976, 1995 and 2009 as gross urban density is 104.8, 78.9 and 65.3 respectively. On the other hand, population grew 368 percent during these 40 years which equals an increase of 4.6 times while city space grew 611 percent (equal to an increase of 7.1 times).

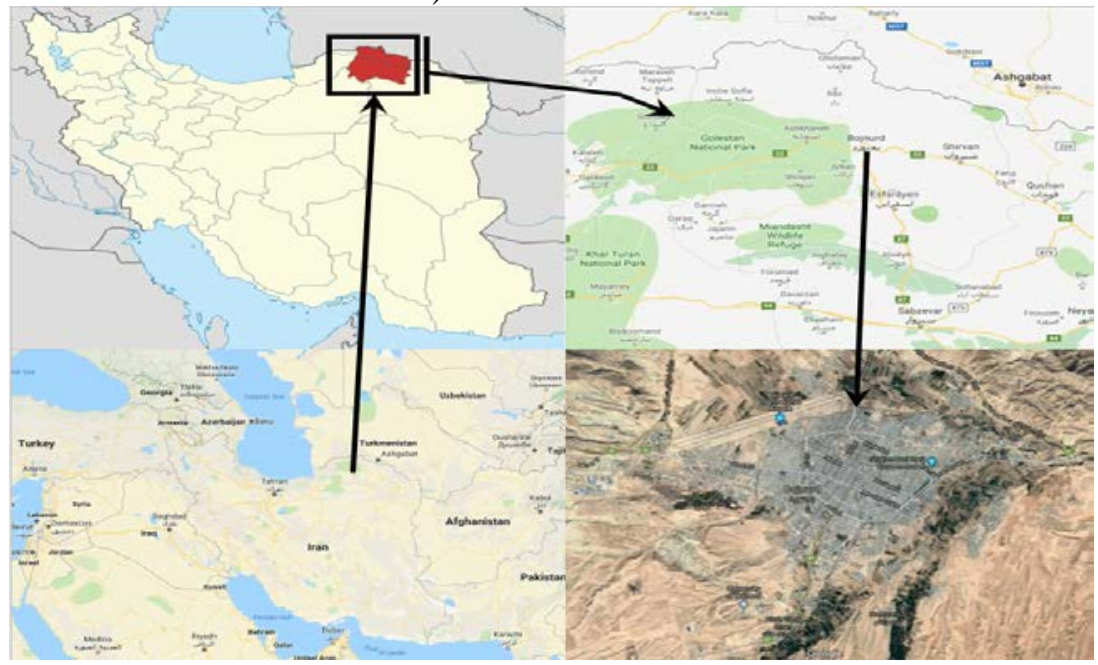

Figure1. Location map of Bojnurd 
Table1: gross urban density of Bojnurd (1941-2016)

\begin{tabular}{|c|c|c|c|}
\hline Year & City space (hectare) & Population & $\begin{array}{c}\text { Gross density } \\
\text { (person per hectare) }\end{array}$ \\
\hline 1941 & 19.5 & 15293 & 153.6 \\
\hline 1956 & 142 & 19253 & 135.5 \\
\hline 1966 & 270 & 31248 & 115.7 \\
\hline 1976 & 450 & 48850 & 108.6 \\
\hline 1986 & 770 & 93392 & 121.2 \\
\hline 1996 & 1653 & 134835 & 82.46 \\
\hline 2006 & 2854 & 186297 & 65.27 \\
\hline 2011 & 3050 & 199791 & 65.5 \\
\hline 2016 & 3200 & 228931 & 71.5 \\
\hline
\end{tabular}

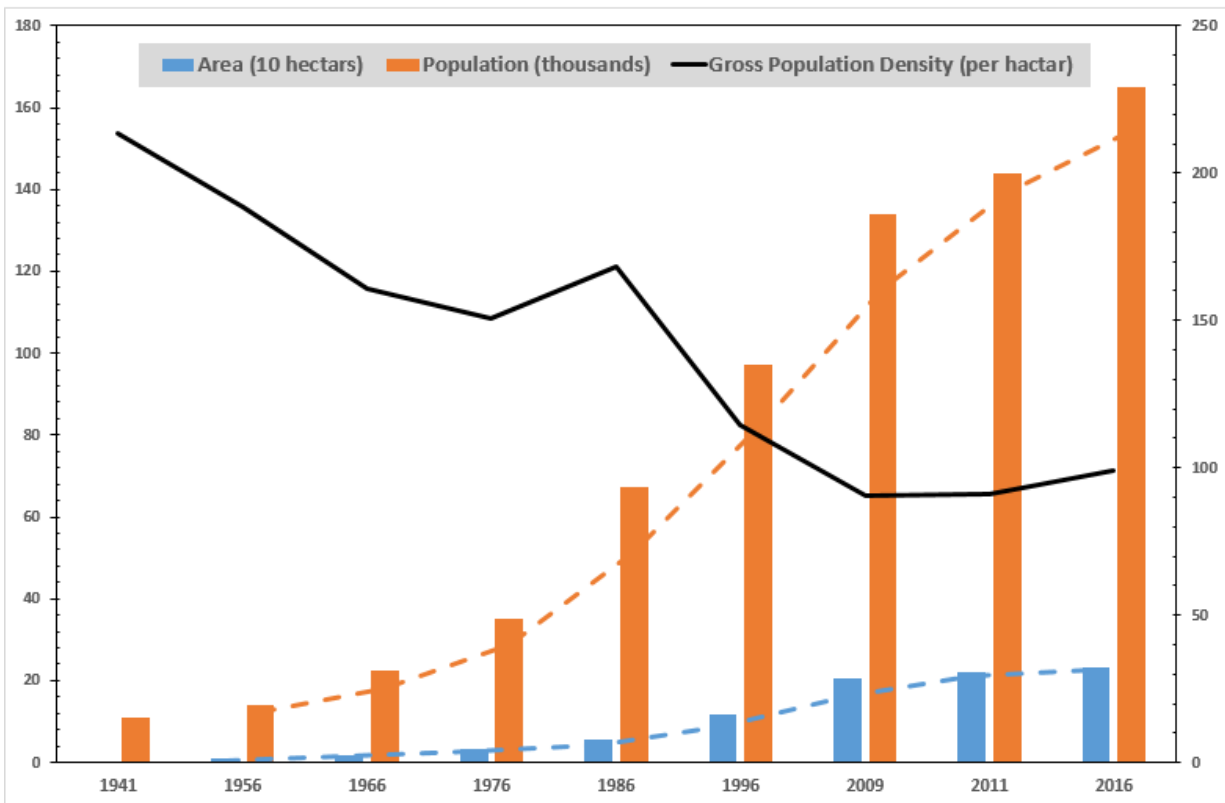

Figure 2. Time series and comparison of city area, population and gross population density of Bojnurd

By analyzing somatic expansion of Bojnurd, we can separate 3 different fabrics which are categorized as Inner, Middle and Outer. Each of these fabrics has different situation according to their creation circumstances and time. In external fabric which mostly has been formed after land reformation period and has grown after Islamic revolution, not following the plans, principles and rules of construction, lack of desired land use in residential areas, sprawl construction and undesirable status of quality and quantity parameters are obvious that explains serious need of control and leading.

Analysis of idle lands in this fabric which is 33.4 percent of the whole 
space indicates the significant sprawl expansion of city during recent decades whereas the least space is belonged to urban service. Table 2 shows a comparison of different land us categories to comprehend somatic features of these lands.

Table 2: Portion of different land use categories from the space of existing fabrics of Bojnurd

\begin{tabular}{|c|c|c|c|}
\hline \multirow{2}{*}{ Land use } & \multicolumn{3}{|c|}{ Portion of land uses from fabrics } \\
\cline { 2 - 4 } & Outer & Middle & Inner \\
\hline Residential & 17.4 & 40.5 & 53.3 \\
\hline Service & 9.4 & 11.3 & 7.5 \\
\hline Idle lands & 33.4 & 6.8 & 7.9 \\
\hline Passage way & 16.3 & 26 & 24 \\
\hline Others & 28 & 15.4 & 7.3 \\
\hline
\end{tabular}

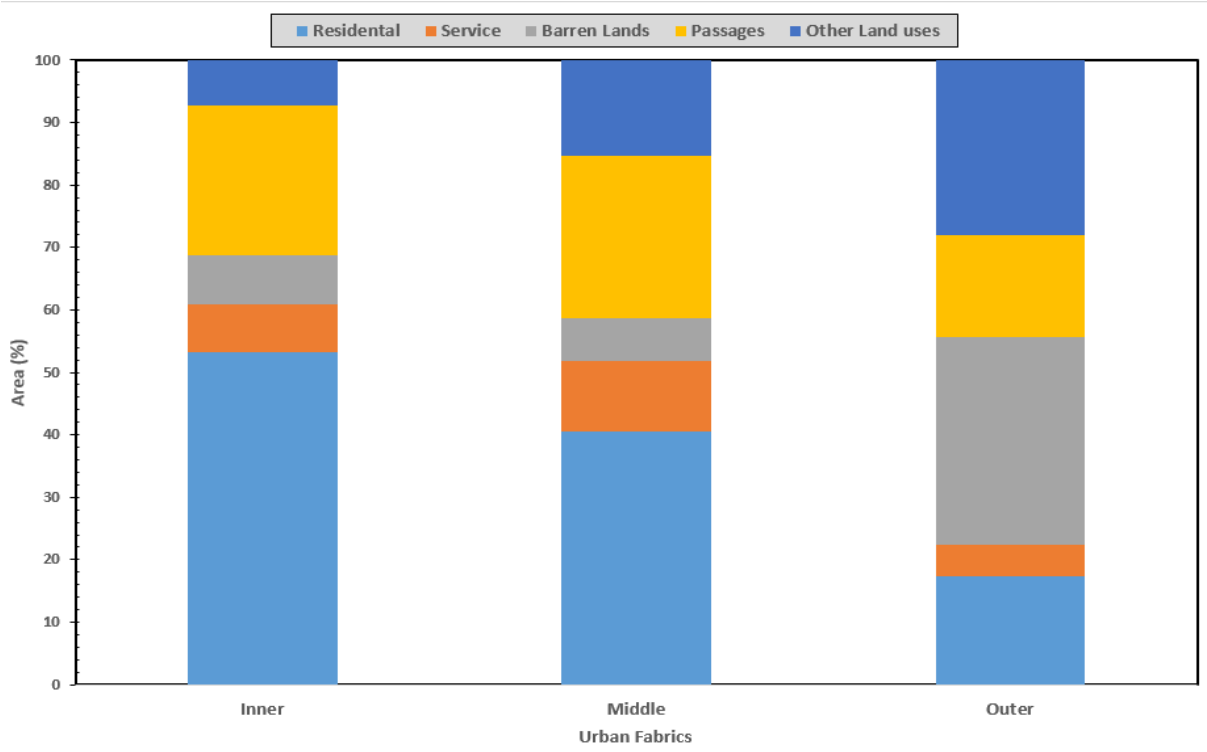

Figure 3. Portion of different land use categories

\section{Geographical location villages of the study and process of their somatic expansion:}

In this research, the villages of the study are categorized in two groups. First category includes some villages that are merged in somatic body of Bojnurd in its somatic expansion and Malkesh and Halghesang are the villages which are the cases of study in this research and were attached to city fabric in comprehensive plan of Bojnurd in 1388 and are a part of urban service now. And second group include those villages which are located around city and in peri-city domain and is under attack of being swallowed by somatic expansion of Bojnurd in its physical development and the case of study are Yengeh Ghaleh and 
Bagherkhan 3. Malkesh and Halghesang are in the south of Bojnurd in the road side of Bojnurd- Esfarayen. Assessment of population growth of these 2 villages during a 30-year period (1976-2016) shows a sharp growth of population (table 3) as their population growth overtakes Bojnurd population growth which expresses that these villages were immigrant status of extra population of Bojnurd because of their cheaper lands and settlements.

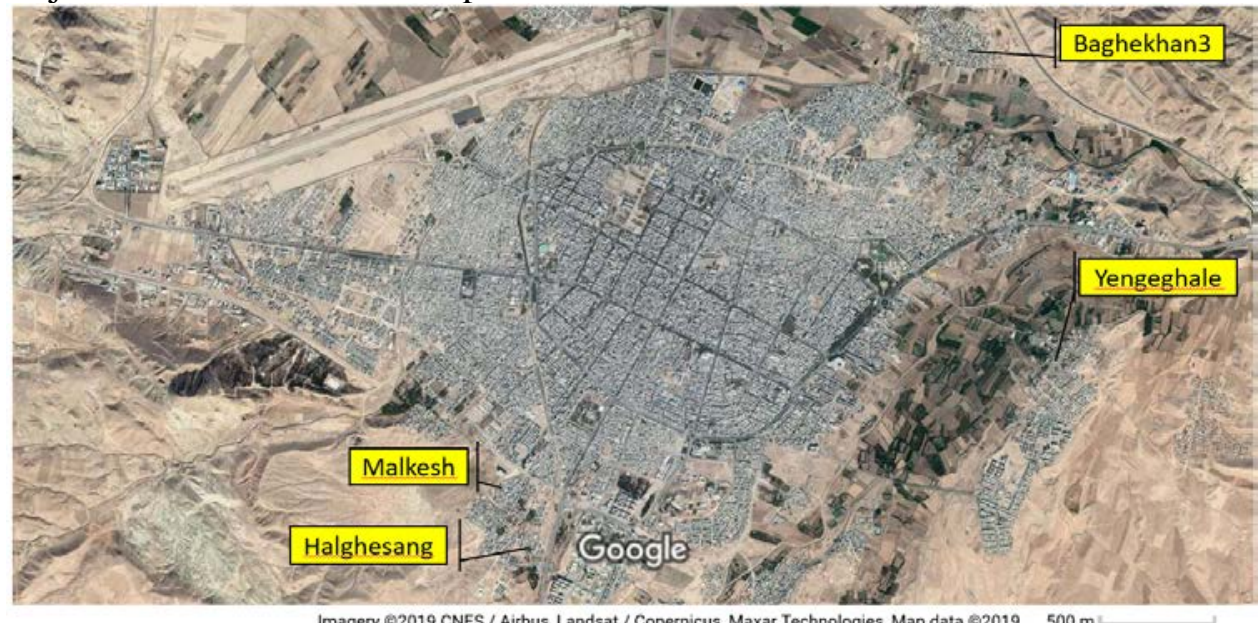

Figure 4. Location of Villages as case study

Table 3: Population Growth rates of Malkesh, Halghesang and MohammadAbad from 1976 to 2016

\begin{tabular}{|c|c|c|c|c|c|}
\hline Village & $1976-1986$ & $1986-1996$ & $1996-2006$ & $2006-2011$ & $1976-2016$ \\
\hline Malkesh & 3.5 & 8 & 7.5 & 6.3 & 6.7 \\
\hline Halghesang & 1.6 & 18.3 & 12.4 & 10.5 & 11.2 \\
\hline MohammadAbad & 5.2 & 9 & 3.4 & 6.5 & 5.9 \\
\hline
\end{tabular}

Yengeghaleh is located in the east of Bojnurd in the vicinity of Valieasr suburb and Bagherkhan 3 is located in the distance of 500 meters of north of city on the route of new cemetery of Bojnurd and analysis of their population growth process indicates the immigrant status of them in recent 3 decades (table 4). Although their population rate is lower than the previous villages but it's still more than Bojnurd population growth. Cheaper land and houses could be some rationales of immigrant status of these 2 villages.

Table 4: Population Growth rates of Yengeghaleh and Bagherkhan 3 between 1355 and 1385

\begin{tabular}{|c|c|c|c|c|c|}
\hline Village & $1976-1986$ & $1986-1996$ & $1996-2006$ & $2006-2011$ & $1976-2016$ \\
\hline Yengeghaleh & 6 & 1.7 & 3.5 & 5.67 & 4.22 \\
\hline Bagherkhan 3 & 2.8 & 6.8 & 5.8 & 12.5 & 6.9 \\
\hline
\end{tabular}




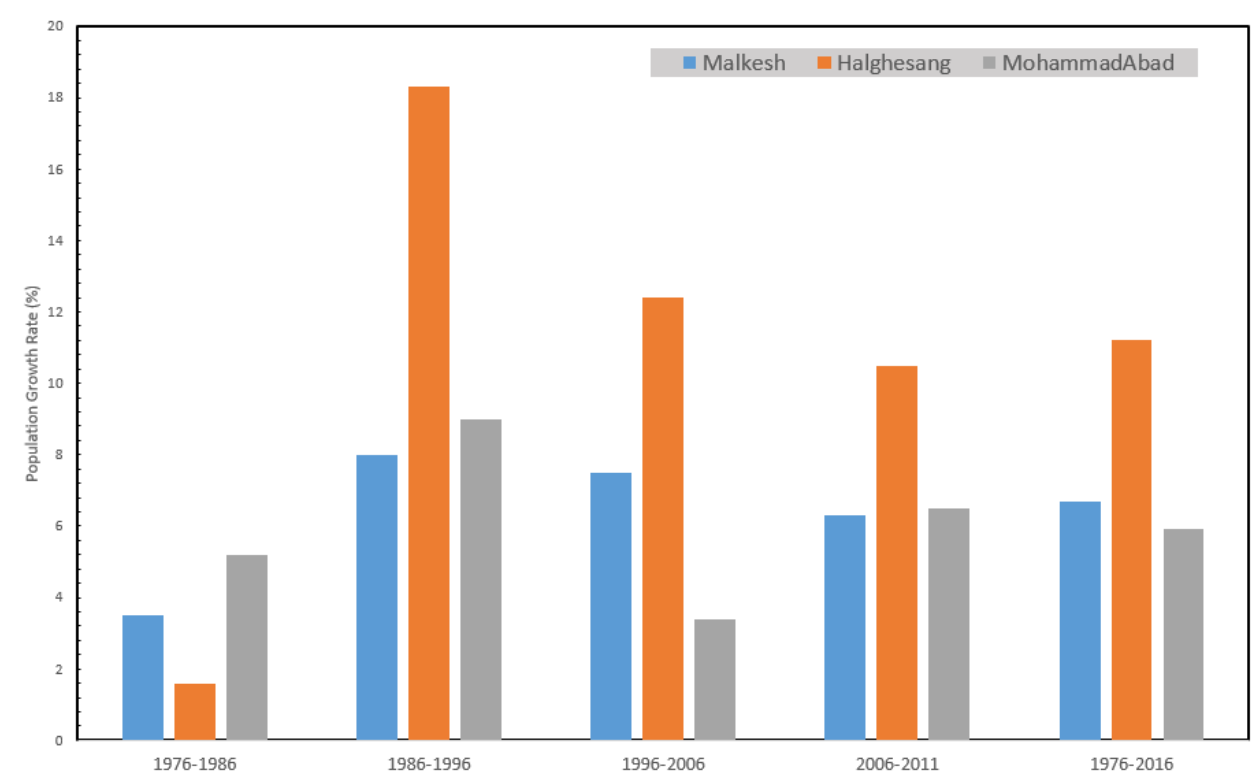

Figure 5. Population Growth rates of Malkesh, Halghesang and MohammadAbad from 1976 to 2016

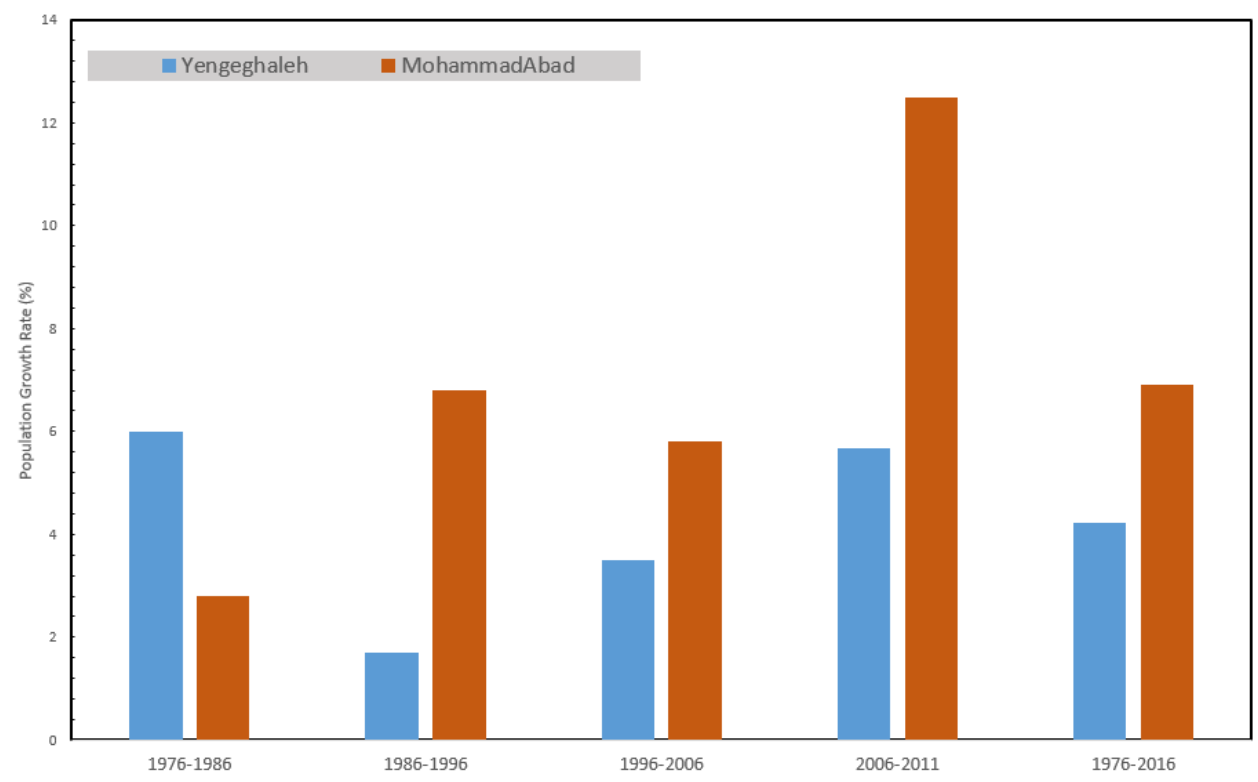

Figure 6. Population Growth rates of Yengeghaleh and Bagherkhan 3 and 1976 to 2016

But this population growth which is under effect of Bojnurd vicinity has caused major transitions in occupation structure and body of these villages that has direct or indirect influences on land use change of agricultural lands and 
gardens. Based on economic features, the results of studies on rural infrastructural development plans show that closer villages to physical domain of the city have less occupants in agriculture (table 5) and this is the main reason of increase of occupants in industry and service parts in Bojnurd.

Table 5: Income portion of the villages occupants in 3 categories

\begin{tabular}{|c|c|c|c|}
\hline Village & Agriculture & Industry & Service \\
\hline Malkesh & 52.6 & 24.6 & 22.8 \\
\hline Halghesang & 2.1 & 91 & 6.8 \\
\hline Yengeghaleh & 85.4 & 4.3 & 10.4 \\
\hline Bagherkhan 3 & 66 & 16 & 18 \\
\hline
\end{tabular}

In terms of service and installation and land use, population growth has also caused a special structure in these villages as residential portion has resulted a decline in service portion which is shown in table 6 .

Table 6: Major existing land use in the villages of study

\begin{tabular}{|c|c|c|c|c|}
\hline Land use & Malkesh & Halghesang & Yengeghaleh & $\begin{array}{c}\text { Bagherkhan } \\
\mathbf{3}\end{array}$ \\
\hline Residential & 41.4 & 42.4 & 43.9 & 69.6 \\
\hline Service & 2.7 & 3.2 & 7.8 & 0.9 \\
\hline Passage way & 23.7 & 30.9 & 20.3 & 12.1 \\
\hline $\begin{array}{c}\text { Agricultural lands } \\
\text { and gardens }\end{array}$ & 1.6 & 18.2 & 4.5 & 1.6 \\
\hline Idle lands & 30.6 & 5.3 & 18 & 15.8 \\
\hline Cemetery & 0 & 0 & 5.5 & 0 \\
\hline Total & 100 & 100 & 100 & 100 \\
\hline
\end{tabular}

\section{CONCLUSION}

Bojnurd has experienced growth in 2 general forms during the time. Organic model that was dominant till Pahlavi and before 1960s land reformations grew smoothly, continuously and slowly, and non-organic model that took place in recent 50 years and passed domination of irregular sprawl expansion which caused creation of external fabrics in different forms of suburbanites (growth of informal settlements), discontinuous development and swallowing the villages around and major problems of this city is also resulted by this growth model which caused loss of integration and spongy development, increasing idle and useless lands and destroying in demand agricultural lands and gardens. In accelerated process of scattered expansion of the city, vast areas are situated in the suburbs as rural fabrics that most agricultural lands are illegally partitioned and came into market and made environmental problems and informal settlements. 
The results of the assessments on urban creep phenomenon of Bojnurd with scattered expansion pattern indicates progress swallowing suburb villages and changing land use from agricultural and gardens in to residential that if this process continues, other villages will also be in danger if this merger (map 1).

The results of these studies show that while Bojnurd population is increasing, the body of this city tends to expand sprawl more quickly and to encroach the lands around which confirms the decline of gross urban density and occupation of idle lands. One of the consequences of this encroachment is swallowing suburb villages that with merging these villages, on one side, agricultural land and gardens disappear and we witness this threat nowadays and in the other side, the balance of land use was harmful to service land use so the accomplished analysis confirms the given theory named "sprawl growth and expansion of Bojnurd has given a rise to land use change of rural agricultural and gardens around city"

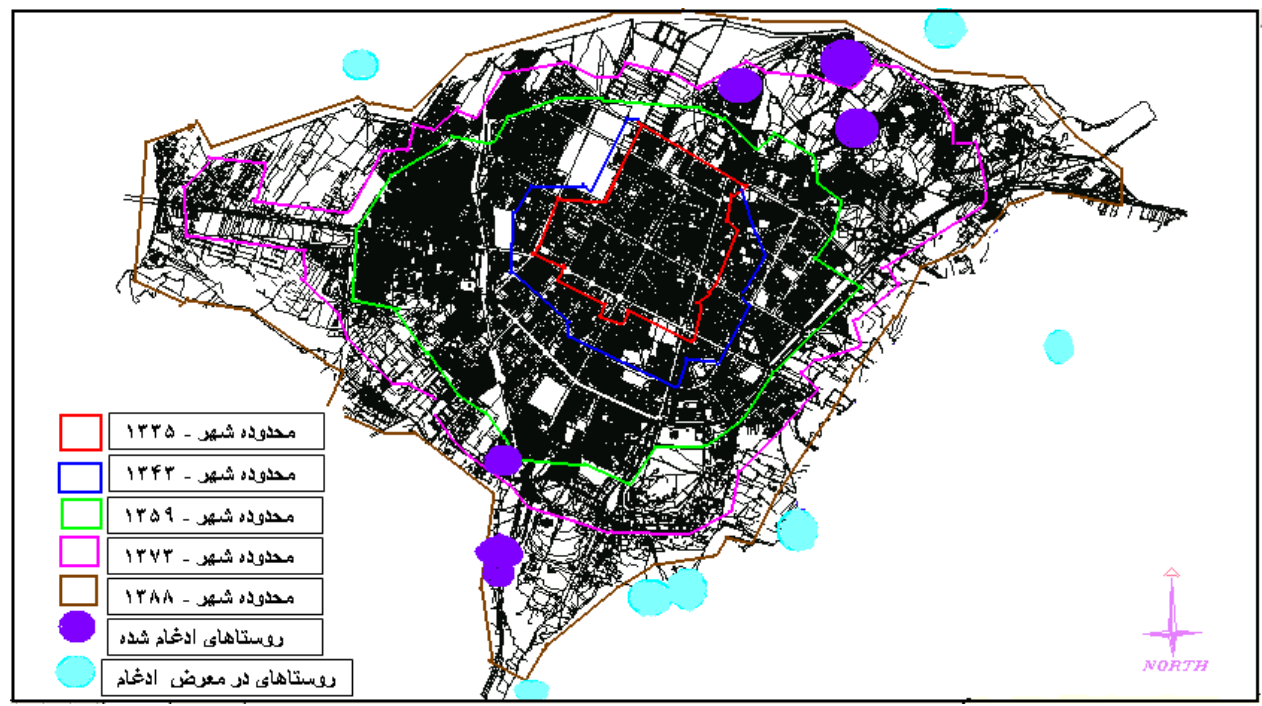

Figure 7. Process of somatic expansion of Bojnurd Status of peri-city villages

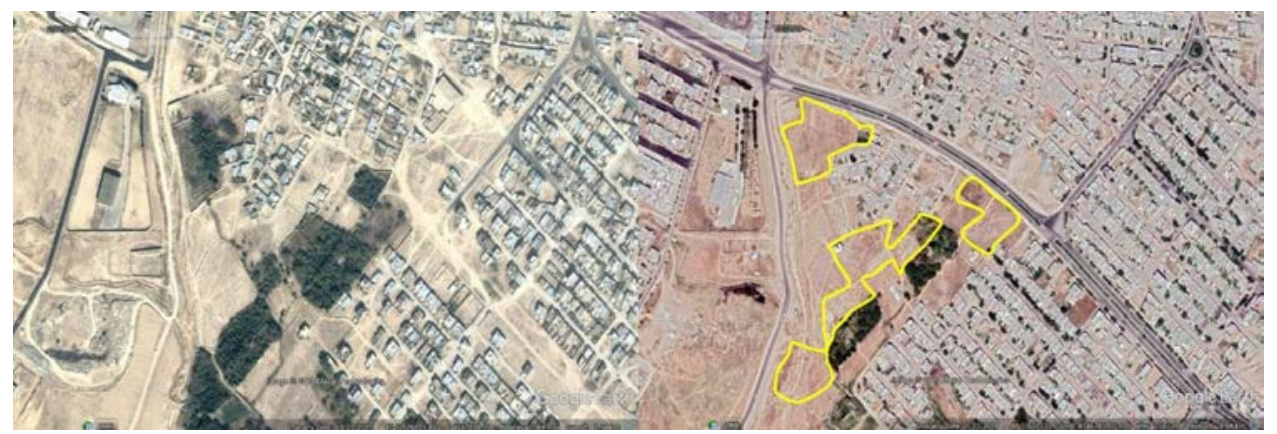

Figure 8. Some Sharp Land Use Changes (Clear Cutting of Gardens) in the South of Bojnurd Between 10/25/2005 (Left) to 7/23/2019 (Right) 


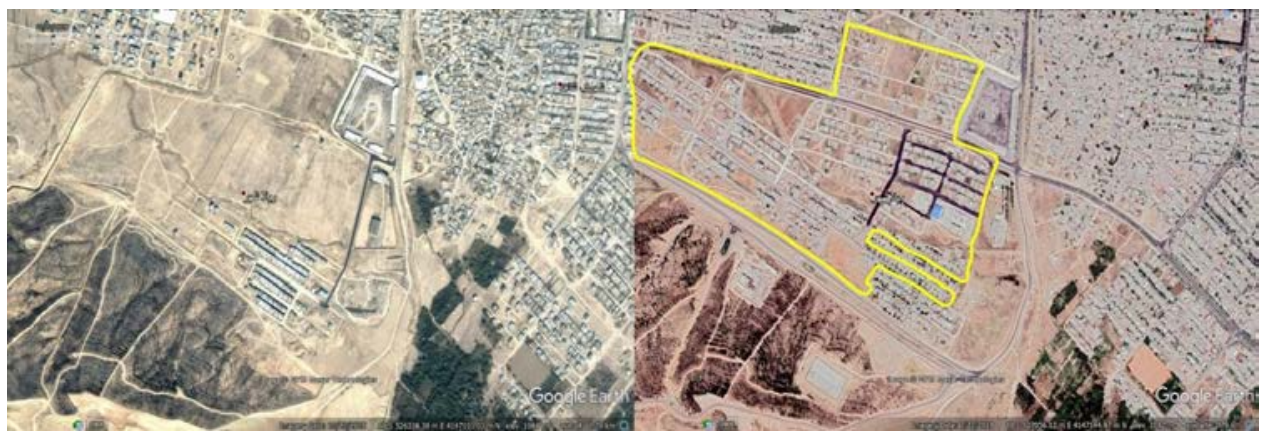

Figure 9. Sharp Land Use Change (Rain Fed Agricultural Lands to Residential Area) in the South West of Bojnurd Between 10/20/2005 (Left) to 7/23/2019

(Right)

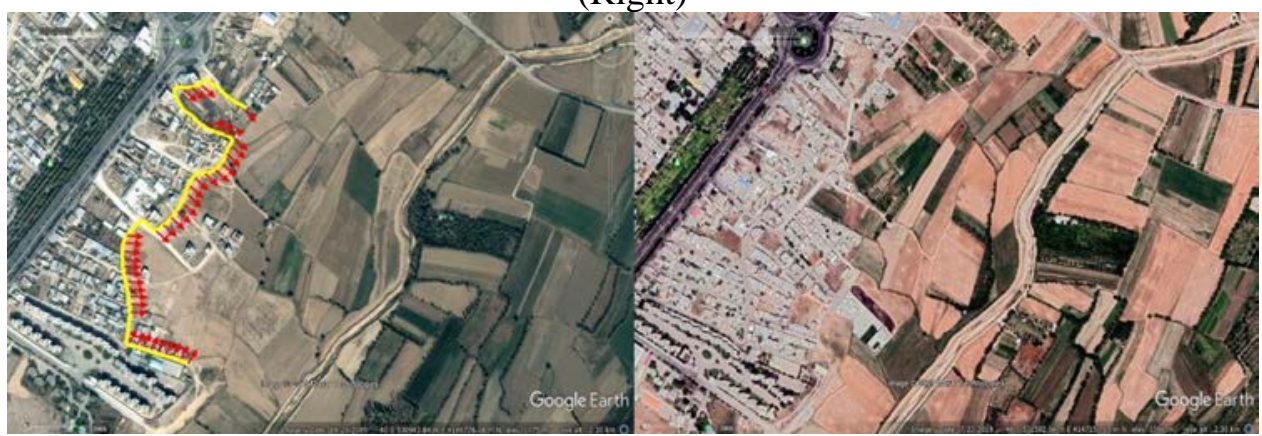

Figure 10. Urban Creep Between 10/20/2005 (Left) to 7/23/2019 (Right) in the East of Bojnurd

\section{RECOMMENDATIONS}

What is deduced from population and somatic assessment of Bojnurd and the villages around is that Bojnurd because of being promoted to be center of the province and accepting better and new zonal roles and new investment and job creation capacities in following decades will be an immigrant city that some emigrants will live in the villages around and this problem will make the agricultural lands and gardens in danger of disappearing more than before so regarding to urban sustainable development and also rural sustainable development, there must be some plans to have these high grade agricultural lands with their desirable landscapes as an opportunity not a threat for sustainable development.

If the settlements located in peri-city areas get led and correct plans get accomplished for protecting their agricultural and gardens landscapes there will be the opportunity for moving toward urban sustainable development and rural sustainable development and if we don't make correct decisions in these areas, they will find a residential approach in form of informal settlements and it will be a threat die sustainable development. Therefore, in the first step we must recognize suburb villages as a part of an integrated system with metropolis that have constitutional impacts on system so then we must see them through 
collision location of city-village-nature in the form of a zonal planning and a combined rural and urban planning and management and regarding to this some recommendations are given as below:

In order to protect agricultural land and gardens of peri-city villages and to prevent them from land use change, we must replace pattern of compressed city instead of scattered city pattern and according to the existence of idle and nonagricultural lands in urban fabric which occupied 24 percent of city space, prevent all kinds of limit rise and control all types of irregular construction out of existing limit seriously and construction of green rings roads and green bows must be included in urban managers' working schedule to prevent sprawl expansion of city and invasion of the city to agricultural lands and gardens especially those between attached city fabric and separate cores of Golestan and Valieasr Suburbs which are talented to get into market.

Precise observation is needed for adjacent villages which are in danger if getting merged with somatic fabric of the city that in this case training village assistants would have a major influence.

Infrastructure development plans of these villages must be up to date and revision off them must be included in planning schedule of housing foundation and providing them must be with advisement of the most eligible and experienced consultants according to social and economic affairs and partnership of people and village managers including village assistant, council and local trustees and finally prevent all kinds of change in land use of agricultural lands and gardens of villages and around them and subjoining must be with the permission of land use change commission.

\section{REFERENCES}

Musallam, A. (2012), Urban sprawl in Palestinian Occupied territories causes consequences and future, Journal environment and urbanization Asia, No 3, pp 121-141.

Azizpoor, M., Hosain Zade Dali, K., Esmail Poor, N. (2009). Investigation of relationship between rapid horizontal growth of Yazd and population movements. Journal of Geography and Environmental Planning of Isfahan University. 20 (2): 105-124. [In Persian]

Robert, B. and Johanna, K. (2006), Housing Finance in Asia, Asia development, Manila, Philipines.

Daneshpour, Z. (2007). Analysis of spatial inequality of pre-urban areas. Journal of Honar-Ha-Ye- Ziba of Tehran University,Vol. 28 (28). [In Persian]

Fajr \& Tosee Consulting Engineering (2008). High level construction feasibility in Bojnurd, Ministry of Building and Urban management. [In Persian]

Fajr \& Tosee Consulting Engineering (2007). Feasibility and preparedness plan of Healthy City: case study of Hamzanlu. [In Persian]

Davis, H. (2000). Social Justice. Tranlated by Hesamiyan \& Haeri \& Monadizadeh, Pardazesh Publication, Tehran. [In Persian] 
Geographical Research group of Jihade-Daneshgahi branch of Mashhad (2004). Infrastructure development plan of Malkesh village. [In Persian]

Geographical Research group of Jihade-Daneshgahi branch of Mashhad (2004). Infrastructure development plan of Yengeghalee village. [In Persian]

Fahime, M. (2008). Infrastructure development plan of Halghesang village. [In Persian]

Fahime, M. (2008). Infrastructure development plan of Bagherkhan3 village. [In Persian]

Naghshe-Jahan Ppars Consulting Engineering (2002). Integrated development plan of Bojnurd, Ministry of Building and Urban management. [In Persian]

Rahnama, R., Gholamreza, A. (2008). A comparative study and analyzing sprawl ratio in the metropolitan cities of Mashhad and Sydney. Geograpgh and Regional Development, 2008 (6), pp. 110-137.

Musavi, S., Mirsattar Ghorbani, R. (2010). Environmental impacts of the expansion settlements case study: the vally of Oskoo. Journal of Geograpghy and Regional Development of Ferwosi University, Vol. 5 (8).

Shlomo, A., Parent, J., Civco, D. (2012),The fragmentation of urban landscapes: global evidence of a key attribute of the spatial structure of cities, 1990-2000, Environment and Urbanization, , 24 (1): 249-283.

Turskis, Z., Zavadskas, K., Jurgis, Z. (2006). Sustainable City Compactness Evaluation on the Basis of GIS and Bayes Rule, International Journal of Strategic Property Management, 10, pp 185-207.

Jurgis, Z., Burinskiene, M., Edmundas, Z., Turskis, Z. (2007). Urbanistic assessment of city compactness on the basis of GIS applying the Copras method, Ekologija, Vol. 53, pp 55-63.

Mohamad, M. (2008). The rate of frame development and extension of Tabriz and its role on changes in using the lands of impact area villages and suburbs (the case study: Alvare-Sofla, Baghe-Maroof, Shadabad and Kondrood Villages. Geography and Development Iranian Journal of Sistan and Baluchestan University, 6(11): 181198. [In Persian]

Tavana, Z., Ghadermarzi, M.H. (2009). Land use changes of peri-urban villages in urban sprawl process case study: Niasar \& Hasanabad villages of Sanandaj. Human Geograpgh Research, Vol. 42 (68). [In Persian] 